\title{
Polímeros, from now onwards published only in English.
}

As promised, from this volume (v27, number1, Jan-Mar/2017) onwards Polímeros is going to publish articles written exclusively in English. They will be an average of 48 articles per year, evenly distributed in four numbers. This was the last step towards becoming a really international scientific journal, which give to all of us a great pleasure in been part of the world community. In the beginning of this year Polímeros has published an extra issue containing the very last 16 accepted articles written in Portuguese.

Recently one of our Associated Editor Prof. João B. P. Soares from University of Alberta, Edmonton, Canada, facing an increase in other duties, has asked us to resign from this position. We lose a great team leader, but we understand his reasons and sincerely acknowledge the work he has done to Polímeros. We still count on him to express his opinion as AdHoc Reviewer in his field of expertise. Thank you Prof. João, keep in touch.

Towards the end of last year the members of the Council Board have approved and implemented the article-charge, to all accepted articles submitted to Polímeros. Up to now authors from $77 \%$ of all accepted articles agreed to help funding the journal. Next time you apply a project do not hesitate to budget funds to publish its results.

Myself, in behalf of the Editorial Board, thanks all our Polymer Community Members for understanding the reason why and accepting the new financial police of Polímeros, this is the warranty it needs to sustain itself in the future ....

Sebastião V. Canevarolo

Editor-in-Chief 